\title{
Enhancing Interdisciplinary Interactions in the College of Engineering and Natural Sciences: Year I
}

\author{
Shirley Pomeranz, Peter LoPresti, Michael Kessler, William Potter, Jerry McCoy, Leslie \\ Keiser, Donna Farrior \\ The University of Tulsa
}

\begin{abstract}
Introduction
A team of faculty members in the College of Engineering and Natural Sciences at The University of Tulsa (TU) has begun work on a National Science Foundation (NSF)-funded Course, Curriculum, and Laboratory Improvement (CCLI) Project (Proposal \# 0410653). This project uses Interdisciplinary Lively Application Projects (ILAPs) ${ }^{1}$ as a vehicle for strengthening connections among the science, engineering, and mathematics departments ${ }^{2}$. The concept of ILAPs was born from a consortium of 12 schools led by the United States Military Academy (USMA) through an NSF funded project entitled Project INTERMATH ${ }^{3}$. ILAPs are interdisciplinary group problem-solving projects designed for undergraduates, co-written by mathematics faculty and science/technology/engineering faculty. These small group projects are designed to foster student interest by being lively. ILAPs motivate students to understand the connections between mathematical tools, concepts, and applications within the broader science and engineering fields. With these projects, STEM students see real-world applications of mathematics in science and engineering.
\end{abstract}

One of the main thrusts of the project is to produce assessment data on the effectiveness of ILAPs in learning. There is much anecdotal evidence to support claims that students benefit in many ways from ILAPs. For example, ILAPs demonstrate how mathematics is used in partner disciplines, give students experience in working and communicating as part of an interdisciplinary team, provide practical experience in the use of technology, etc. However, formal assessments on the pedagogical effectiveness of ILAPs have not yet been done, and we hope to make an initial contribution to such analysis.

Another focus of the project is the enhancement of interaction between the mathematics faculty and those of the engineering disciplines in order to provide a more cohesive instructional environment. Although mathematical concepts and principles remain the same, terminology and notation differ among the disciplines. In order for faculty to be able to inform students of these connections, faculty must be aware of terminology and notation beyond their own disciplines. A strong cooperative environment allows faculty to share ideas and concerns regarding instruction, and identify needs for improving student preparation. Therefore, strengthening the connections among faculty can be beneficial to both students and faculty.

\section{Project Design}

The project is designed to introduce ILAPs throughout the mathematics curriculum by phasing in their implementation over several semesters. In the first academic year (first two semesters), ILAPs from each of the engineering disciplines are introduced into the foundational calculus

"Proceedings of the 2005 American Society for Engineering Education Annual Conference \& Exposition Copyright (C) 2005, American Society for Engineering Education 
courses (Calculus I and II), with two ILAPs (projects) per semester per class. In each course, one section of the course is assigned a traditional calculus project instead of the ILAP in order to provide a control group for evaluation and assessment. The goals of this first year are (1) to assess the effectiveness of ILAPs, (2) determine what factors impact the effectiveness, and (3) make recommendations for future implementation in the mathematics and engineering curricula. Assessment is coordinated and provided by an external independent evaluator. Using the results and recommendations from the first year, ILAPs will be introduced into additional courses in the second year, such as Calculus III, and the ILAPs for Calculus I and II will be refined and reevaluated. In addition, the ILAPs will form a basis for class projects in the individual disciplines to reinforce the connection between engineering concepts and the underlying mathematics. Results are assessed by the independent evaluator and a national project advisory board.

In addition to the ILAP work, two computer workshops and faculty colloquia are being held each semester to help strengthen the interaction between STEM faculty. The computer workshops are designed to provide basic instruction in the use of computational software packages that are in common use in all disciplines, and they are open to faculty and students alike. The initial focus is on MATLAB and Mathematica, and the practical use of these packages for problem solving. The faculty colloquia are an open forum for faculty to discuss ideas, problems, and needs regarding ILAPs and mathematics and engineering instruction in general. The intent is to use these colloquia to organize initiatives and programs for the following semesters.

\section{Description of Early Stages of Project}

This two-year project is in its initial stages, having begun in late summer 2004. We have teamtaught two Calculus I ILAPS during the fall 2004 semester. The first ILAP was an electrical engineering/math ILAP, "Designing an Electric Car", dealing with an RC-circuit and exponential decay. The second ILAP was a chemistry/math ILAP, "Chemical kinetics", involving the decay of phenolphthalein in the presence of sodium hydroxide and, again, the mathematics of exponential decay. Selected students published their reports at the project web site (http://www.ilaps.utulsa.edu). We also have a control class of students who do projects that are not interdisciplinary and not hands-on. The non-ILAP projects were "Newton's method" and "Fitting a line to data" (determining the slope of the line; the vertical-intercept was given as zero). The ILAPs and non-ILAPS were assigned concurrently to their respective calculus sections.

This is our first attempt at introducing ILAPs into our courses, although we have used group projects in the calculus courses prior to this. We have not previously used interdisciplinary or hands-on features of projects. Our ILAPs have both of these features. For our future comparisons we will be using non-ILAP projects that more directly compare with the corresponding ILAPs. We will construct both using the same underlying problem and mathematics, but include interdisciplinary and hands-on aspects only in the ILAPS.

We constructed our ILAPs and non-ILAPs keeping in mind students' comments from previous projects. We gave students information packets containing the following (which are posted at our web site): project description and assignment, grading policy and related information, technical report format and writing guide, sample report, information on working effectively in small groups, and small group peer evaluation forms.

\footnotetext{
"Proceedings of the 2005 American Society for Engineering Education Annual Conference \& Exposition Copyright (C) 2005, American Society for Engineering Education
} 
Douglas Grouws, Mathematics Education, University of Missouri, is the external independent evaluator in charge of the assessments. He is assisted by Leslie Keiser, a graduate student at TU. At this stage, we have mainly anecdotal observations and students' comments, although by the project's completion we will have statistical data. We emphasize that the data we have at this stage are preliminary.

\section{Student Reactions}

Students completed questionnaires after each of the projects. Teams consisting of four students worked on each project for two weeks. There were two weeks between the completion of the first project and assignment of the second project. Some student comments about the ILAPs are included below.

ILAP \#1; "Designing an Electric Car":

- I don't really like the projects. They seem as just extra filler material.

- This project was a little complicated for our group. We were still lost after asking questions.

- I think the project was a good experience. However it would be better if you had included new concept (theories) that we could learn about; that would be more interesting.

- Explain things less technical in the beginning and then get more formal and technical.

- It would help if the class introduction included more explanation of the background information and the related equations - what the equations mean and how they are related to each other.

- Our group did not spend but about 20 minutes on the calculus of this project. The majority of our time was spent in trying to figure out what we were to find and in writing the report. Since this is a calculus class not an abstract problem solving class let us stick to calculus. If these projects are to be continued, I recommend revision to more strongly emphasize the calculus aspect of the projects.

- I did like the project and enjoyed working with my group members. It was more beneficial to me in a way to get to know people rather than learning.

- The project seemed to only relate to engineering majors, so my interest in it was rather low, due to the fact that I am biology major. Is there any possible way to relate it to the other majors? ....I felt a little lost as to being able to find a good starting point.

ILAP \#2; "Chemical kinetics":

- Explain first. Then experiment.

- Offer a little more support on using mathematical computer programs to present information in the paper.

- Let students decide on group members. Doing something more exciting than watching a display as a chemical reaction progressed would be nice. This was a much better, much more organized project versus project \#1. I hate these projects they are just confusing.

- Good project, but it was a time sink. For the amount of time I put into it, I learned a minimal amount of information. I thought that it was a better project than the previous one, but the concepts were still very hard to figure out.

"Proceedings of the 2005 American Society for Engineering Education Annual Conference \& Exposition Copyright (C) 2005, American Society for Engineering Education 
These comments raise questions. Why did students not come to the instructors and/or graduate teaching assistants for help? Or, if they did, why was the help not sufficient? Or was it? Most teams recognized (eventually) the problems to be solved and then solved them. We need to construct clearer ILAPS, perhaps use existing ones to start, or at least have clearer communication channels between instructors and students. How do we keep the interdisciplinary components without watering down the calculus aspects? How open-ended should the project description be in order to be of benefit to students without discouraging them? We will wrestle with these and other issues as our project expands to use ILAPs in Calculus II and Calculus III classes.

Some student comments about the non-ILAPs follow.

Non-ILAP \#1; “Newton's method”:

- Maybe instead of telling the group exactly everything to do, they should have to experiment a little on their own. For example, prompt them to find other places where Newton's method does or does not work well.

- I would have liked it to be more hands on.

- ...Prefer a project more directly connected to a real world application, where the target mathematical topic is observed physically, rather than through direct calculation. This project involved only work on a calculator and was more an exercise in report generation. This project would be used best as practice/preparation to orient students before moving in to a more complex or involved project. Mathematics influence on physical behavior would be more interesting than topics observed entirely on our graphing calculator.

- The project really did a good job of teaching and gave a better understanding of Newton's method. But I still don't understand how I can apply Newton's method to the real world.

- The Newton's method project lacked because it was just reading the book and reiterating that. The other classes' project was cool, so why was ours so boring in comparison?

- I would prefer a project that has more to do with the real world, but the ILAPS project seemed to be much more difficult.

Non-ILAP \#2; "Fitting a line to data":

- Let us pick our own groups, whole or part. You could use groups of four, have each person pick one other person they would like to work with, and pair up the groups randomly. Then we can pick a person we know is dependable, while the random pairing will make us meet new people.

- Make the projects more interesting and more involved, more thought driven and less reading driven.

- Why don't we do something more related to chemistry or physics, like other sections, since it's very close the material we study this semester?

- More hands on.

- Collect data yourself, as opposed to being given data points.

- The project was more interesting than the first one on Newton's Method, but I would like to do a lab project.

"Proceedings of the 2005 American Society for Engineering Education Annual Conference \& Exposition Copyright (C) 2005, American Society for Engineering Education 
- I would recommend making the project focus on a practical application so that student will be better prepared to apply calculus to real world applications, rather than focusing on analytical problems.

- I like the level of difficulty of the project, but I would like a more hands on type of assignment.

Our ILAPs students seemingly would have preferred no project, whereas the non-ILAPs students seem to want ILAPs. Is there a message here? We have our work set out for us in terms of these student comments. If our ILAPs are to be a valuable component of our calculus courses, then we need to act appropriately on these comments.

\section{Preliminary Results}

On the first day of class, students were given a Conceptions of Mathematics Inventory. This inventory will be given again at the end of this project for comparison. Students answered on a Leichart scale from 1 to 6 , with 1 being strongly disagree and 6 being strongly agree. Using the student responses, a mean was calculated for each dimension. The inventory consisted of 7 dimensions including: composition of mathematical knowledge (mean:3.88), structure of mathematical knowledge (4.33), status of mathematical knowledge(3.72), doing mathematics (4.60), validating ideas in mathematics (4.14), learning as constructing and understanding (4.21), and mathematics as a useful endeavor (5.15). The most important thing to notice is that the students slightly disagreed that mathematics was a dynamic field, but they strongly agreed that mathematics was a useful endeavor. This information is important to use in understanding the student's thoughts concerning each ILAP that was implemented during the semester.

ILAP \#1, "Designing an electric car", was assigned to two sections of Calculus I at the same time that non-ILAP \#1, "Newton's method", was assigned to the control section. Four weeks later, ILAP \#2, "Chemical kinetics", was assigned to two sections of Calculus I at the same time that non-ILAP \#2, "Fitting a line to data", was assigned to the control section. Each of the three calculus sections had about forty students. Students completed questionnaires as they submitted their projects, but before receiving their grades. The questions from the student questionnaires follow.

1. How much time (hours) did you spend working on this project? (Q1)

2. How many group meetings did you have? (Q2)

3. The class introduction helped me understand the project better than if I had just read through the project description. (Q3)

4. I was satisfied with how my group worked together on this project. (Q4)

5. This project helped me make a connection between Calculus and the real world. (Q5)

6. By completing this project, I gained a better understanding of how resistors and capacitors work (ILAP \#1) or chemical kinetics (ILAP \#2) or Newton's method (nonILAP \#1) or least squares curve-fitting (non-ILAP \#2). (Q6)

7. This project was interesting. (Q7)

8. I would like to do more of these kinds of projects in the mathematics courses I take. (Q8)

Numerical responses to questions \#3 through \#8 were assigned the interpretations in Table 1.

"Proceedings of the 2005 American Society for Engineering Education Annual Conference \& Exposition Copyright $\odot$ 2005, American Society for Engineering Education 
Table 1. Interpretations of numerical response values

\begin{tabular}{cccccc}
\hline $\begin{array}{c}\text { Strongly } \\
\text { disagree }\end{array}$ & Disagree & $\begin{array}{c}\text { Slightly } \\
\text { disagree }\end{array}$ & Slightly agree & Agree & $\begin{array}{c}\text { Strongly } \\
\text { agree }\end{array}$ \\
\hline 1 & 2 & 3 & 4 & 5 & 6 \\
\hline
\end{tabular}

The average values of the student responses to these 8 questions are given in Table 2. In order to show the general distribution for each question, box and whisker plots were created with the data for each question. Figure 1 shows a box and whisker plot for questions 1 and 2 for both the ILAP sections and the non-ILAP sections. The line in the box represents the median data value. The top of the box represents the Upper Quartile (UQ) - the data value located halfway between the median and the largest data value), while the bottom of the box represents the lower quartile (LQ) - the data value located halfway between the median and the smallest data value. The interquartile distance (IQD) is defined as the distance between the Upper and Lower Quartiles (UQ-LQ). Outliers are points whose value is either: greater than UQ $+1.5 * \mathrm{IQD}$ or less than LQ $-1.5^{*} \mathrm{IQD}$. Figure 2 shows the numerical response distributions for questions 3 through 8.

Table 2. Average values of student responses

\begin{tabular}{cccccccccc}
\hline Project & $\begin{array}{c}\text { Number } \\
\text { of } \\
\text { Students }\end{array}$ & Q1 & Q2 & Q3 & Q4 & Q5 & Q6 & Q7 & Q8 \\
\hline ILAP \#1 & 59 & 5.8 & 3.5 & 4.4 & 4.7 & 4.0 & 4.1 & 3.8 & 3.3 \\
Non-ILAP \#1 & 42 & 5.1 & 3.5 & 4.7 & 5.0 & 3.5 & 5.3 & 4.0 & 4.0 \\
& & & & & & & & & \\
ILAP \#2 & 70 & 6.6 & 3.6 & 4.8 & 4.8 & 3.7 & 3.8 & 3.6 & 3.3 \\
Non-ILAP \#2 & 38 & 4.4 & 2.8 & 5.2 & 4.7 & 4.1 & 4.9 & 4.2 & 4.1 \\
\hline
\end{tabular}




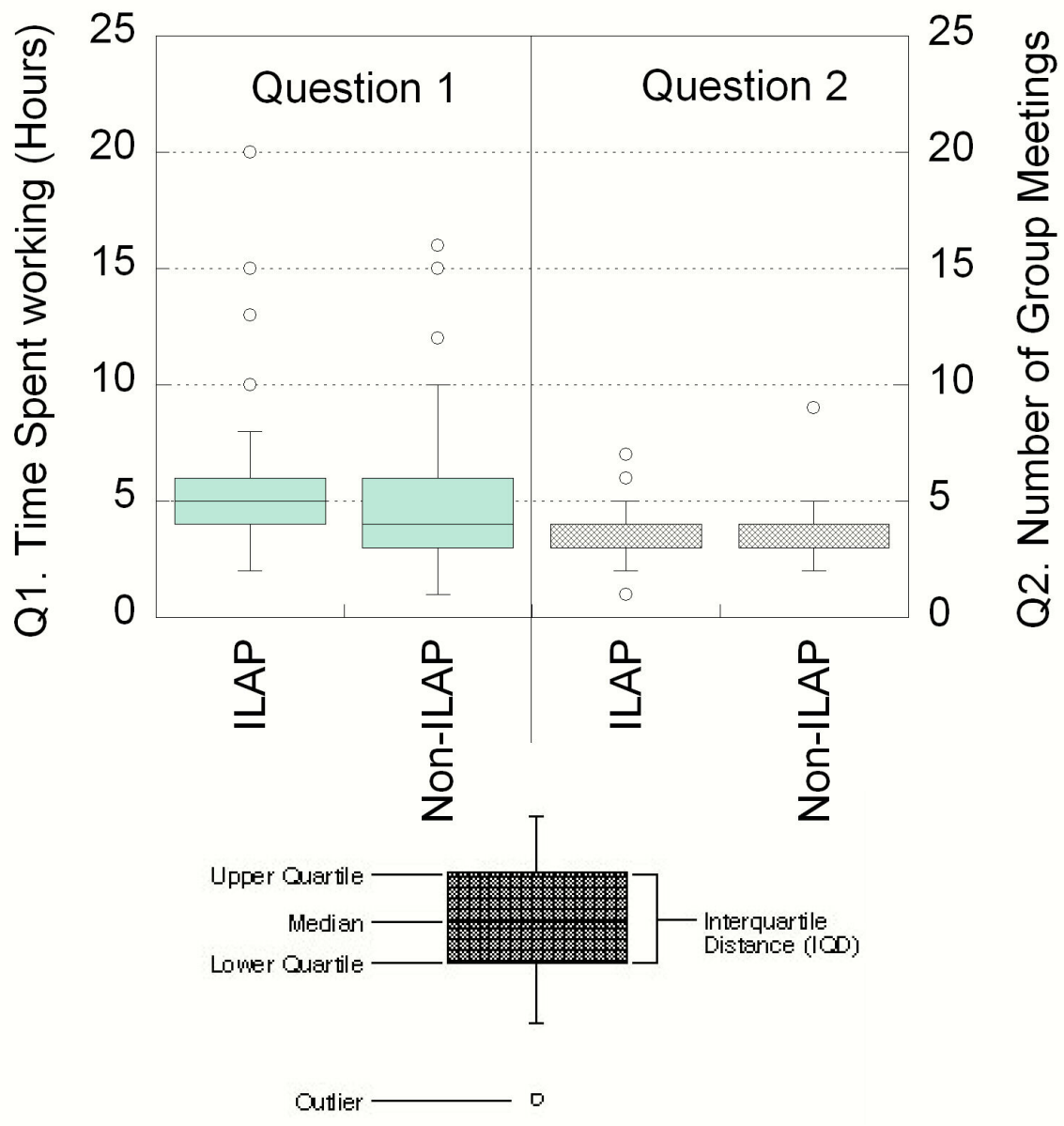

Figure 1. Box and Wisker Plot for Question 1 and 2 


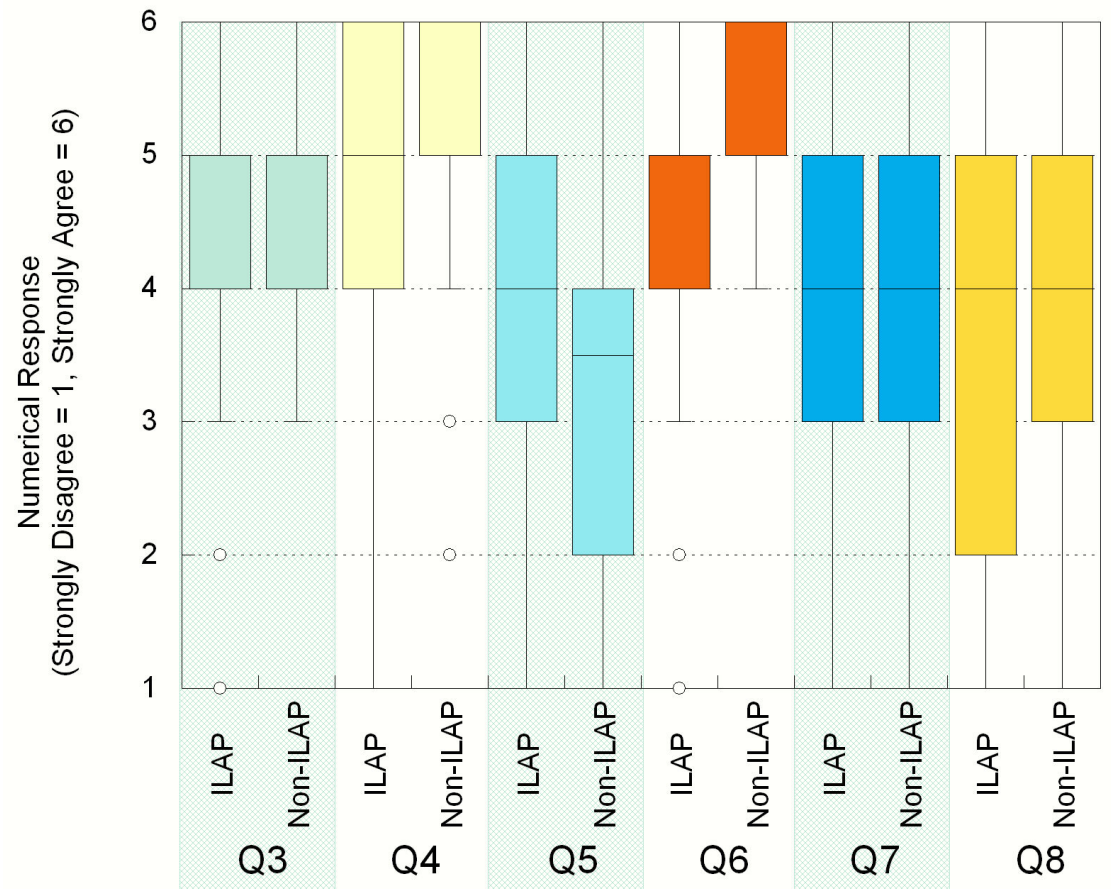

Figure 2. Box and Wisker Plot for Questions 3 through 8

\section{Software Workshops}

The Mathematica workshop was held in October 2004. The MATLAB workshop was held in December 2004. Workshops were open to faculty, graduate students, and transfer students. The workshops were designed for beginning users of the programs and focused on the fundamental operations and capabilities of the programs. Basic instructional materials were supported by extensive hands-on materials and a number of examples demonstrating how to apply each program's capabilities to engineering problems. Participants were also directed to additional resources made available by faculty within the College of Engineering and Natural Sciences at $\mathrm{TU}$, as well as external resources. The workshops were very well received by all participants.

\section{Colloquium}

Project faculty met with other college faculty in December to share information on the initial evaluations and observations regarding the project, and to discuss common curriculum concerns. The student evaluations from the ILAPs noted previously were shared, along with anecdotal observations regarding ILAP effectiveness. Consensus recommendations included strengthening the calculus element and improving the content of the student pamphlets and in-class discussion to improve clarity.

The participating faculty targeted two significant areas of concern outside of the ILAPs. First, incoming students had weak skills in the area of matrices and linear algebra, most notably in the heavy reliance on calculators and numerous errors in the area of solving systems of linear equations. One faculty noted a decrease in the amount of instruction received by the students at the high school level as a contributing factor. Possible solutions to the problem will be discussed at the next colloquium. 
Second, all faculty expressed the need for an introductory course in scientific computing to provide all incoming students with a basic set of skills needed for their expected course work. Excel, Mathematica, and MATLAB were identified as the most common packages in use across the college. Over $45 \%$ of all Engineering and Science faculty indicated the reliance of Excel in their course work, but rather remarkably, no faculty from the Mathematics department indicated that they used Excel in their courses. A goal was set to develop this introductory course for scientific computing in the spring semester and propose it for inclusion in the engineering curriculum.

\title{
Acknowledgements
}

Funding for this work has been provided by the NSF CCLI Program (Proposal \# 0410653).

Project faculty from the TU Department of Mathematical and Computer Sciences are Thomas Cairns, Dale Doty, Donna Farrior, William Hamill, Kevin O'Neil, and Shirley Pomeranz.

Project faculty from TU science and engineering departments include William Potter and Dale Teeters, Dept. of Chemistry and Biochemistry; Peter LoPresti and Douglas Jussaume, Dept. of Electrical Engineering; Bryan Tapp, Dept. of Geosciences; Michael Kessler, Dept. of Mechanical Engineering; and Jerome McCoy, Dept. of Physics and Engineering Physics.

\author{
Bibliography \\ ${ }^{1}$ D.C. Arney, editor, Interdisciplinary Lively Application Projects, MAA, 1997. \\ ${ }^{2}$ Felder, Richard M. and Brent, Rebecca, "The intellectual development of science and engineering students - \\ Part 2: Teaching to promote growth”, Journal of Engineering Education, Oct. 2004, pp. 279-291. \\ ${ }^{3}$ http://www.projectintermath.org, Project INTERMATH.
}

\section{SHIRLEY POMERANZ}

Shirley Pomeranz is an Associate Professor of Mathematics in the Department of Mathematical and Computer Sciences at The University of Tulsa. She is the 2005 ASEE Mathematics Division Program Chair and is a member of the Editorial Advisory Board for The International Journal of Engineering Education. Her interests include support of women in mathematics and research involving the finite element method.

\section{PETER LOPRESTI}

Peter LoPresti is an Associate Professor of Electrical Engineering at The University of Tulsa. His interests include the support of undergraduate participation in research, optical networks, fiber optic sensors, sensor networks, and artificial vision. He is a member of both IEEE and ASEE.

MICHAEL KESSLER

Michael Kessler is an Assistant Professor of Mechanical Engineering at The University of Tulsa. His research interests include the mechanics and processing of polymers and polymer matrix composites, thermal analysis, fracture mechanics, and biologically inspired materials. He is a member of ASME and ASEE.

"Proceedings of the 2005 American Society for Engineering Education Annual Conference \& Exposition Copyright (C) 2005, American Society for Engineering Education 
WILLIAM POTTER

William Potter is a Professor of Chemistry in the Department of Chemistry and Biochemistry at The University of Tulsa.

JEROME MCCOY

Jerome McCoy is an Applied Assistant Professor in the Department of Physics and Engineering Physics at The University of Tulsa.

\section{LESLIE KEISER}

Leslie Keiser is a graduate student in the Department of Geosciences at The University of Tulsa.

DONNA FARRIOR

Donna Farrior is an Applied Assistant Professor in the Department of Mathematical and Computer Sciences at The University of Tulsa. 